\section{(2) OPEN ACCESS}

\title{
Adverse employment histories and allostatic load: associations over the working life
}

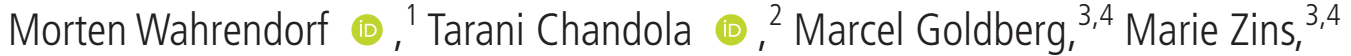 \\ Hanno Hoven, ${ }^{1}$ Johannes Siegrist ${ }^{5}$
}

\begin{abstract}
- Additional supplemental material is published online only. To view, please visit the journal online (http://dx. doi.org/10.1136/jech-2021217607)
\end{abstract}

${ }^{1}$ Centre for Health and Society, Institute of Medical Sociology, Heinrich-Heine-University of Düsseldorf, Medical Faculty, Düsseldorf, Germany

${ }^{2}$ Department of Social Statistics, University of Manchester,

Manchester, UK

${ }^{3}$ Population-Based

Epidemiologic Cohorts Unit, INSERM, UMS 011, Villejuif, France

${ }^{4}$ Faculté de Médecine, Paris University, Paris, France

${ }^{5}$ Senior Professorship Work Stress Research, Heinrich-HeineUniversity of Düsseldorf, Medical Faculty, Düsseldorf, Germany

\section{Correspondence to}

PD Dr Morten Wahrendorf Centre for Health and Society, Institute of Medical Sociology, Heinrich-Heine-University of Düsseldorf, Medical Faculty, Düsseldorf, Nordrhein-

Westfalen, Germany; wahrendorf@uni-duesseldorf.de

Received 2 July 2021

Accepted 26 September 2021

\section{ABSTRACT \\ Background Most studies on the health impact of} occupational stress use single-point measures of stress at work. This study analyses the associations of properties of entire employment trajectories over an extended time period with a composite score of allostatic load (AL). Methods Data come from the French CONSTANCES cohort, with information on adverse employment histories between ages 25 and 45 and a composite score of AL (based on 10 biomarkers, range $0-10$ ) among people aged 45 or older (47680 women and 45035 men). Data were collected by questionnaires (including retrospective employment histories) or by health examinations (including blood-based biomarkers). We distinguish six career characteristics: number of temporary jobs, number of job changes, number of unemployment periods, years out of work, mode occupational position and lack of job promotion.

Results For both men and women, results of negative binomial regressions indicate that adverse employment histories are related to higher levels of AL, particularly histories that are characterised by a continued disadvantaged occupational position, repeated periods of unemployment or years out of work. Findings are adjusted for partnership, age and education, and respondents with a health-related career interruption or early retirement are excluded.

Conclusions Our study highlights physiological responses as a mechanism through which chronic stress during working life is linked to poor health and calls for intervention efforts among more disadvantaged groups at early stages of labour market participation.

\section{INTRODUCTION}

The concept of allostatic load (AL) has been used to understand the potential biological pathways between exposure to recurrent or long-lasting stressors and the development of stress-associated disorders. ${ }^{1} \mathrm{AL}$ refers to the cumulative burden of adaptive physiological responses to stressors or environmental threats that result in a dysregulation of bodily response patterns and functional impairment of different organ systems (including cardiovascular, metabolic and immune systems). Multiple epidemiological studies have documented its relevance when studying social determinants of health, where the concept of AL helped to understand health consequences of adverse psychosocial conditions. ${ }^{2}$ Adverse psychosocial conditions at work define one such condition and are usually measured according to theoretical models of work stress. These models help to identify conditions at work that are most likely to activate bodily stress reaction, such as jobs characterised by high demands and limited opportunities of exercising control and autonomy (the demand control model ${ }^{3}$ ), or jobs where workers receive limited rewards and recognition for invested efforts (the effort-reward imbalance $\operatorname{model}^{4}$ ). Several studies have reported associations of work stress (as measured by the two work stress models) with AL, either assessed by single indicators or composite AL scores. ${ }^{5-7}$

However, these work stress models focus on a typical work environment and assume a long-lasting full-time employment characterises a person's main or continuous job. They neither include information on the chronicity of exposure nor on the cumulative and repeated experience of stress in different jobs, thus disregarding intraindividual changes of working and employment conditions over time. ${ }^{8}$ In fact, as an example, a recent study highlights that the accumulation of work- related stress is linked to a higher level of AL. ${ }^{9}$ Therefore, these theoretical notions need to be extended by shifting the analytical perspective from stable to dynamic work arrangements, considering entire trajectories and their properties over an extended time period. This shift is further justified by profound changes of working life due to economic globalisation and technological transformation, resulting in a growing proportion of employment relations that are characterised by flexibility, instability and insecurity. ${ }^{10}$ Extending research along these lines corresponds to a life course perspective, ${ }^{11}$ specifically, the idea of considering employment histories that cover an extended time frame. ${ }^{8}$

With the increasing availability of retrospective information from occupational cohort studies collecting data on exposure duration, timing and its sequential character over time (including job changes and periods of unemployment), this analytical shift can now be applied. ${ }^{12-15}$ In this context, a typology of health-adverse employment histories has been proposed with a distinction between precarious careers (eg, temporary contracts and frequent job changes), discontinuous careers (eg, unemployment interruptions) and disadvantaged working careers (eg, cumulative disadvantaged occupational positions or downward mobility). ${ }^{16}$ As in the case of the work stress models mentioned previously, these types of employment histories involve-although to a different extent-recurrent threats to, or loss of important psychosocial needs of working persons, such as job security and continuity, ${ }^{17}$ control and autonomy, ${ }^{3}{ }^{18}$ and fairness and 
reward. ${ }^{419}$ It is therefore likely that working under these circumstances promotes the initiation and progression of disease later on. ${ }^{20}$

Along these lines, this paper analyses associations between properties of entire employment trajectories between ages 25 and 45 , and a composite score of AL. In doing so, we extend current knowledge in two ways: first, building on previous evidence on relationships between psychosocial stress at work and AL, we examine whether this association holds true when assessing entire working careers and their properties over an extended time period rather than static working conditions. Second, with an emphasis on AL, this study eludicates pathways from a chronically adverse work environment to a stress-associated disease development.

\section{METHODS}

\section{Data source}

Our study uses latest data from the French CONSTANCES project, $^{21}$ a population-based cohort study that relies on a random sample of people aged 18-69 years that are insured by the French General Health Insurance Fund $85 \%$ of the French population). This covers all salaried workers, professionally active or retired and their family, as well as self-employed and agricultural workers that are insured through a family member. The baseline data collection takes place in 22 national health screening centres and started in 2012 until early 2020, with currently more than 217000 participants. Data in this study were collected by self-administered questionnaires (including retrospective information on employment histories) and as part of a clinical health examination at baseline (including biomarkers of AL and blood samples). For this study, baseline data are available for 186501 participants (aged 18-73 years at baseline) with baseline assessment between 2012 and 2019.

\section{Study population}

Our study relies on a subsample of 96193 men and women aged 45 or older who worked at least once between age 25 and 45 (and thus had employment histories with potential change or stability). Then, to address potential reversed causality (with ill health causing specific employment histories), we exclude people with a health-related career interruption prior to age 45 (3.4\% of the initial sample, 3235 participants), and respondents who retired prior to age 45 (probably due to health-reasons) are not included either (additional 243 participants). This results in a final study sample of 92715 participants (47680women and 45035 men). Details on sample selection are summarised as flowchart in the supplementary material (online supplemental figure 1).

\section{Measures}

Adverse employment histories

CONSTANCES provides retrospective information on each job respondents had (including contract type, occupational position, begin and end) and on potential career interruptions that lasted 6 months or longer (eg, health and unemployment). Combining these data allow us to rearrange the data into a state sequence format, where the data contain a variable that describes the occupational situation for each age between 25 and 45 (covering 21 years). On this basis, we ascertained the following six career characteristics-all referring to employment histories between age 25 and 45: (1) number of jobs with temporary contract (per 10 years in paid work) and (2) number of job changes (per 10 years in paid work) as available indicators of 'precarious careers', (3) number of unemployment interruptions and (4) years out of work as available indicators of 'involuntary interruptions', and (5) the mode occupational position between age 25 and 45 and (6) lack of job promotion as indicators of 'cumulative disadvantages'. The mode occupational position is based on the longest held job (or the most recent in case of two-mode jobs) and measured with seven categories according to the European Socio-Economic Classification scheme. ${ }^{22}$ Selfemployed and agricultural workers were grouped into one class, as well as higher-grade blue collar workers and highergrade white collars (because of small numbers resulting from the sample strategy). Lack of promotion was measured in terms of 'no promotion' or 'failed promotion' (ie, upward and downward mobility processes). Unemployment interruptions measure the number of interruptions due to unemployment. Years out of work counts the number of years without paid work (three categories). Finally, since number of temporary jobs and number of job changes may depend on years in paid work, we calculated the respective numbers per 10 years in paid work (eg, number of temporary jobs/years with paid work $\times 10$ ) that we regrouped into three categories. Table 1 shows details for each variable (including information on missing values).

\section{Allostatic load}

$\mathrm{AL}$ is measured with an index based on 10 biomarkers from the baseline clinical examination. These biomarkers cover four systems involved in $\mathrm{AL}^{23}$ : the cardiovascular and pulmonary systems (systolic blood pressure, diastolic blood pressure and lung function); the anthropometric system (waist to hip ratio); the metabolic system (fasting glycose, ratio of total cholesterol (TC) to high-density lipoprotein (HDL) cholesterol (TC:HDL), triglycerides (TGs), low-density lipoproteins and creatinine clearance rate (CCR); and the immune and inflammatory system (white blood cell (WBC) counts). Lung function is based on the ratio of forced expiratory volume in $1 \mathrm{~s}$ to forced vital capacity $\left(\mathrm{FEV}_{1}: \mathrm{FVC}\right)$, measured with a standard handheld Vitalograph spirometer using the highest of three measurements. For calculating the CCR, we used the Cockcroft and Gault formula. ${ }^{24}$ The six blood-based biomarkers were considered valid if participants had been fasting for at least 8 hours. To create the index, we followed the common procedure, ${ }^{2}$ and created a count-based summary measure of AL that ranges from 0 to 10 , based on sexspecific high-risk quartiles for each biomarker (each coded 0 for 'not at risk' and 1 for 'at risk'). Lowest quartiles were used for CCR and FEV1:FVC (where low values indicated high AL) and the highest quartiles in all remaining cases (where high values indicated high AL). To contribute to the overall AL-index, participants had to have information for at least one biomarker of each one of the four systems covered, and in case participants still had missing values for single biomarkers, they were considered not at risk (' 0 '). Hence, only respondents who had no information for one or more dimensions were excluded from the analysis (3418 participants, less than $4 \%$ of the final sample). This strategy makes maximum use of available data and guarantees that people still contribute in case information is available for the four systems while adopting a conservative approach of handling missing values. Details on each biomarker, with summary measures, number of observations and sex-specific cut-off points, are presented in table 2 , and the online supplemental material includes information on its application (online supplemental table 1).

\section{Additional variables}

Alongside sex and age, we also included a variable measuring at which screening centre the data were collected, partnership 


\section{Original research}

Table 1 Sample description: observations (number) and percentage (col \%) or mean and SD, by sex ( $n=92715$ )

\begin{tabular}{|c|c|c|c|c|c|}
\hline & \multirow[b]{2}{*}{ Categories or range } & \multicolumn{2}{|l|}{ Women } & \multicolumn{2}{|l|}{ Men } \\
\hline & & Number & Col \% or mean (SD) & Number & Col $\%$ or mean (SD) \\
\hline Age (years) & $45-73$ & 47680 & $57.20(7.26)$ & 45035 & $57.63(7.35)$ \\
\hline \multirow[t]{2}{*}{ Partnership* } & Living with partner & 33476 & 71.5 & 36151 & 81.8 \\
\hline & Living as single & 13368 & 28.5 & 8045 & 18.2 \\
\hline \multirow[t]{3}{*}{ Educationt } & Low & 5692 & 12.1 & 4856 & 11.0 \\
\hline & Medium & 16980 & 36.2 & 18410 & 41.7 \\
\hline & High & 24188 & 51.6 & 20864 & 47.3 \\
\hline \multirow[t]{2}{*}{ Current work situation } & In paid work & 26877 & 56.4 & 24706 & 54.9 \\
\hline & Not in paid work & 20803 & 43.6 & 20329 & 45.1 \\
\hline \multirow[t]{3}{*}{ Temporary jobs (per 10 years in paid work) } & No temporary job & 39569 & 83.0 & 39544 & 87.8 \\
\hline & One or less temporary job & 5900 & 12.4 & 4690 & 10.4 \\
\hline & More than one temporary job & 2211 & 4.6 & 801 & 1.8 \\
\hline \multirow[t]{3}{*}{ Job changes (per 10 years in paid work) } & No change & 17303 & 36.3 & 13694 & 30.4 \\
\hline & Two or less changes & 23522 & 49.3 & 26481 & 58.8 \\
\hline & More than two changes & 6855 & 14.4 & 4860 & 10.8 \\
\hline \multirow[t]{3}{*}{ Number of unemployed periods } & No unemployment period & 40857 & 85.7 & 40533 & 90.0 \\
\hline & One unemployment period & 5439 & 11.4 & 3623 & 8.0 \\
\hline & $2+$ unemployment periods & 1384 & 2.9 & 879 & 2.0 \\
\hline \multirow[t]{3}{*}{ Years out of work } & No years out of work & 23530 & 49.3 & 30768 & 68.3 \\
\hline & $1-5$ years out of work & 12104 & 25.4 & 10327 & 22.9 \\
\hline & $6+$ years out of work & 12046 & 25.3 & 3940 & 8.7 \\
\hline \multirow[t]{8}{*}{ Mode occupational position } & Large employers, higher managers and professionals & 3823 & 8.0 & 7168 & 15.9 \\
\hline & Lower managers and professionals & 16920 & 35.5 & 9381 & 20.8 \\
\hline & Intermediate employee & 11646 & 24.4 & 7184 & 16.0 \\
\hline & Small employers and self-employed & 744 & 1.6 & 1114 & 2.5 \\
\hline & Lower-grade white collar workers & 4207 & 8.8 & 1190 & 2.6 \\
\hline & Skilled workers & 757 & 1.6 & 5406 & 12.0 \\
\hline & Semiskilled or unskilled workers & 1815 & 3.8 & 3111 & 6.9 \\
\hline & Main position unknown & 7768 & 16.3 & 10481 & 23.3 \\
\hline \multirow[t]{3}{*}{ Lack of promotion } & Promotion & 7334 & 15.4 & 9119 & 20.2 \\
\hline & No promotion & 39243 & 82.3 & 34361 & 76.3 \\
\hline & Failed promotion & 1103 & 2.3 & 1555 & 3.5 \\
\hline AL index $\ddagger$ & $0-10$ & 45858 & $2.35(1.75)$ & 43439 & 2.38 (1.71) \\
\hline
\end{tabular}

*1675 participants had missing values for partnership (1.8\%).

†1725 participants had missing values for education (1.9\%).

¥Based on measurement approach, 3418 participants had missing values for AL index (3.7\%).

AL, allostatic load.

Table 2 Distribution of the allostatic load biomarkers

\begin{tabular}{|c|c|c|c|c|c|c|c|}
\hline Biological system & Biomarker & Unit & Mean & SD & Number & Cut-off Men & Cut-off Women \\
\hline \multirow[t]{3}{*}{ Cardiovascular and pulmonary system } & Systolic blood pressure & $\mathrm{mm} \mathrm{Hg}$ & 132.37 & 17.20 & 90234 & $>146$ & $>138$ \\
\hline & Diastolic blood pressure & $\mathrm{mm} \mathrm{Hg}$ & 78.54 & 9.86 & 90234 & $>87$ & $>82$ \\
\hline & $\mathrm{FEV}_{1}: \mathrm{FVC}$ & & 0.79 & 0.07 & 66891 & $<0.75$ & $<0.76$ \\
\hline Anthropometric system & Waist to hip ratio & waist (cm)/hip (cm) & 0.88 & 0.09 & 91853 & $>0.99$ & $>0.87$ \\
\hline \multirow[t]{5}{*}{ Metabolic system } & Fasting glucose & $\mathrm{mmol} / \mathrm{L}$ & 5.52 & 0.94 & 89223 & $>5.99$ & $>5.56$ \\
\hline & Total cholesterol to HDL ratio & & 4.01 & 1.48 & 87732 & $>4.92$ & $>4.11$ \\
\hline & Triglyceride & $\mathrm{mmol} / \mathrm{L}$ & 1.21 & 0.74 & 89041 & $>1.59$ & $>1.27$ \\
\hline & Low-density lipoprotein & $\mathrm{mmol} / \mathrm{L}$ & 3.66 & 0.93 & 87624 & $>4.20$ & $>4.27$ \\
\hline & Creatinine clearance rate & Creatinine $(\mu \mathrm{mol} / \mathrm{L})$ & 93.02 & 24.02 & 89284 & $<83.87$ & $<71.08$ \\
\hline Immune and inflammatory system & White blood cell counts & Counts (cell $10^{9} / \mathrm{L}$ ) & 6.06 & 1.66 & 90738 & $>6.90$ & $>6.80$ \\
\hline
\end{tabular}

FEV 1 :FVC, ratio of forced expiratory volume in $1 \mathrm{~s}$ to forced vital capacity; HDL, high-density lipoprotein. 
situation (regardless of marital status), labour market status (in paid work or not) and participants' educational level. The latter is measured according to the International Standard Classification of Educational Degrees (ISCED) 2011 that we regroup into 'low' (preprimary, primary or lower secondary education, ISCED 0-2), 'medium' (upper secondary or post-secondary education, ISCED 3-4) and 'high' (first and second stage of tertiary education, ISCED 5 or higher).

\section{Analytical strategy}

All analyses are conducted for men and women separately, and we started with a sample description and pairwise correlations of all components of AL index. We then estimated a series of mixed regression models (multilevel models with individuals nested in screening centres) to study associations between the career characteristics and the AL index. Specifically, as the AL index was overdispersed (variance greater than the mean), we applied mixed effects negative binomial models for count data (number of AL risk indicators). ${ }^{25}$ Because the number of missing data was small (see table 1 for details), we conducted complete case analyses. The Results section presents estimated coefficients together with CIs (95\%) and p values. Furthermore, since coefficients are difficult to interpret, we also show average marginal effects (AMEs) and summarise predicted levels of AL (average adjusted predictions) in figure 1. More specifically, we applied the 'margins' procedure in Stata, ${ }^{26}$ where the average adjusted predictions of levels of AL are calculated for each category of the career characteristics (based on our regression models). AMEs then represent the difference in adjusted predictions to the reference group. We report estimates of two models. Model 1 is calculated for each career characteristic separately and is adjusted for potential confounders age (linear and squared because of nonlinear association), education and partnership (both included as categorical variable). Model 2 includes all career characteristics simultaneously (with same adjustments). As such, model 1 allows evaluation of the total effect of each characteristic on AL, and model 2 helps to explore which of the career characteristics may still have a direct effect after conditioning for the remaining characteristics, that is, the partial effect after removing contributions through other career characteristics. ${ }^{27}$ We also report results of
Women
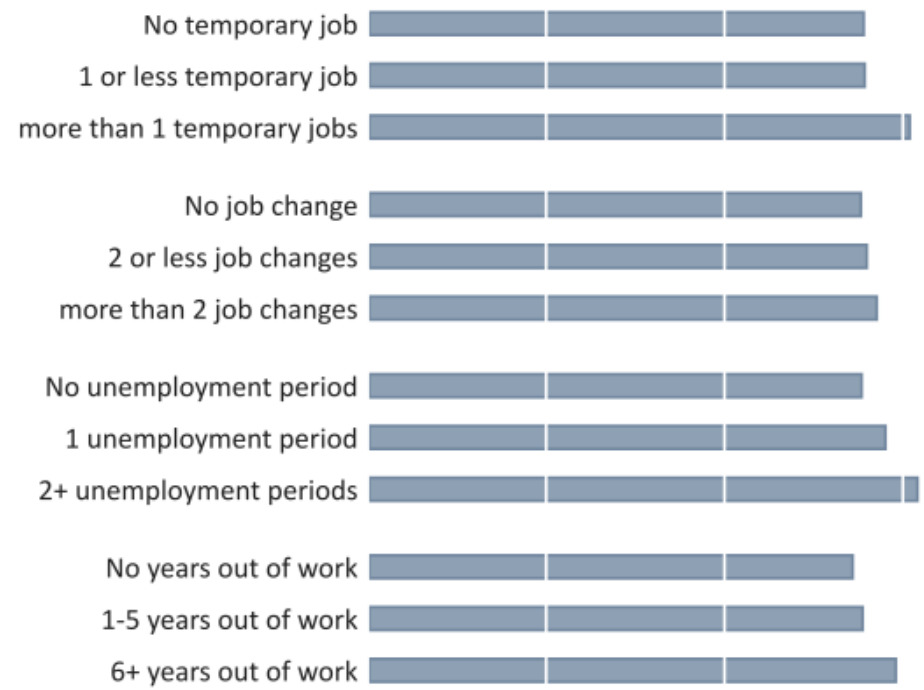

Higher salariat Lower salariat

Intermediate employee

Small employers and self-employed

Lower grade white collar worker

Skilled worker

Semi- or unskilled worker

Main position unknown
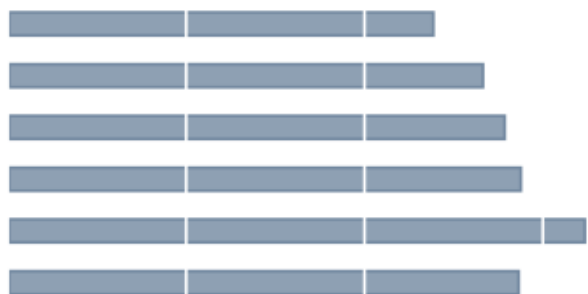

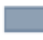

$\square$
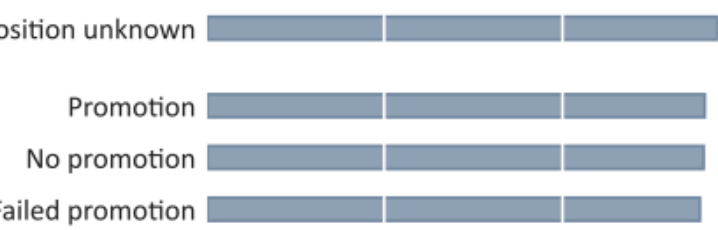

1.5

2

2.5

Men
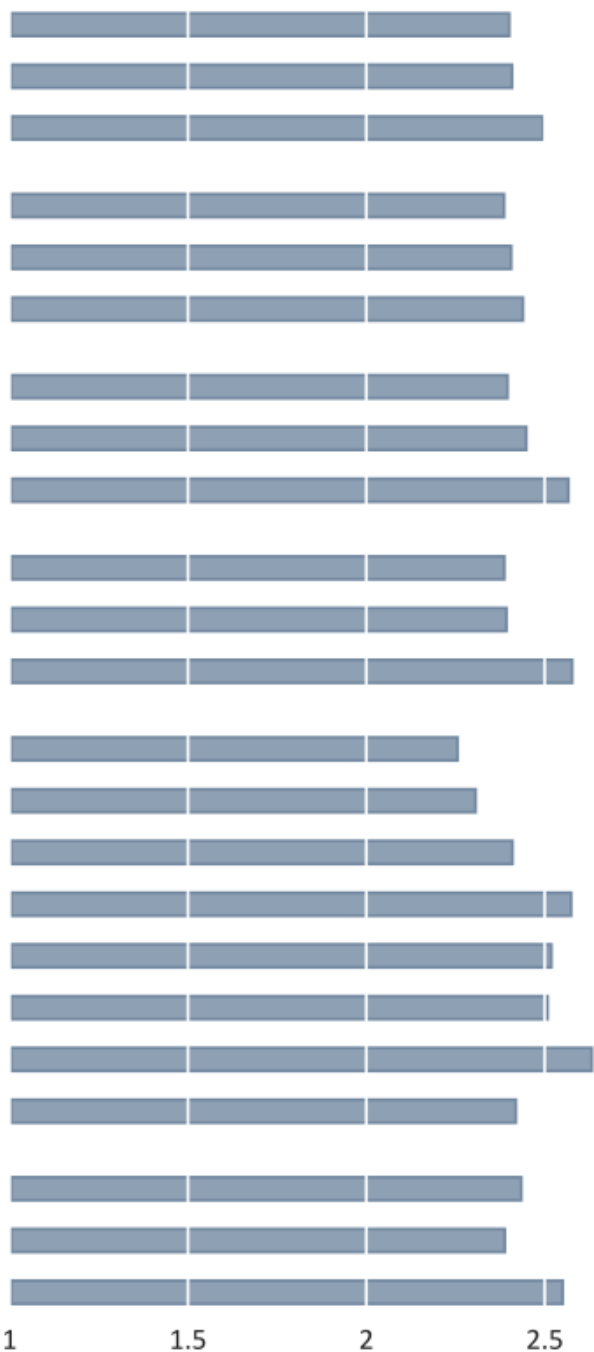

\section{Predicted levels of allostatic load}

Figure 1 Predicted levels of allostatic load by adverse employment histories, estimated from coefficients of model 1 in tables 3 and 4 . Number of temporary jobs and number of job changes are numbers per 10 years in paid work. 
linear multilevel regression models for each AL biomarker (with same adjustments as in model 1 , presented in online supplemental tables 4 and 5). In these models, outcomes were logtransformed in case of skewness (ie, WBC counts, blood sugar levels, ratio of total to HDL cholesterol, TGs and lung function) and standardised to enable comparisons.

As part of sensitivity analyses, models were recalculated with adjustments of reported health conditions at the time of the AL measurement (body mass index (BMI) (linear) and activity limitations (Global Activity Limitation Instrument). All calculations and graphs are produced with Stata V.16.1.

\section{RESULTS}

Table 1 shows that the sample consists of slightly less men than women (45035 men vs 47680 women), with an average age of 57 years for both sexes and the majority in paid work. When comparing employment histories between men and women, we see that men had spent more years in paid work, had fewer temporary jobs and worked in more advantaged occupational positions. Based on our definition of the AL index, we see that scores were similar between sexes, with less than $4 \%$ of missing values and a mean score of 2.35 for women and 2.37 for men (representing the average times of having a high-risk group profile across all biomarkers). For less than 2\% of observations, information on partnership or education was missing. Correlations between all biomarkers of AL (presented in online supplemental table 2) were generally low in all cases, with highest values between two measures of the metabolic system (ratio of total to HDL cholesterol and TGs).

Results of our main research question are presented in table 3 for women and in table 4 for men, with four findings worth noting. First, we see that men and women who mainly worked in a disadvantaged occupational position have a higher $\mathrm{Al}$ score with $\mathrm{p}$ values providing strong evidence against the null hypothesis. For example, the AMEs of model 1 (representing the difference in predicted AL scores) indicate that women who mainly worked as semiskilled or unskilled workers have a 0.43 higher score compared with managers and professionals (for men 0.38 higher). Likewise, women and men who had two or more unemployment periods have higher scores compared with those without unemployment period ( 0.16 higher for women and 0.17 higher for men), as well as those who were out of the labour market for 6 or more years (women: 0.12, men: 0.19 higher than continuously working). Second, focussing on men, we also see that men who reported failed promotion had slightly higher AL scores (0.12 higher scores), and, focussing on women, we found that a higher number of temporary jobs (per 10 years in paid work) was related to higher scores ( 0.13 higher scores). Third, we found no clear associations for men and women who had frequent job changes. Fourth, when comparing results between model 1 and model 2, findings remain consistent (with the only exception of unemployment in case of men), thus suggesting

Table 3 Association between career characteristics and AL index for women $(n=44786)$ : negative binomial regression coefficients $(\beta)$, Cls, $p$ values and AMEs

\begin{tabular}{|c|c|c|c|c|c|c|c|c|c|}
\hline & & \multirow[b]{2}{*}{$\boldsymbol{\beta}$} & \multicolumn{2}{|l|}{ Model 1} & \multirow[b]{2}{*}{ AME } & \multirow[b]{2}{*}{$\beta$} & \multicolumn{2}{|l|}{ Model 2} & \multirow[b]{2}{*}{ AME } \\
\hline & & & $\mathrm{Cl}(95 \%)$ & $P$ value & & & $\mathrm{Cl}(95 \%)$ & $P$ value & \\
\hline \multirow{2}{*}{$\begin{array}{l}\text { Temporary jobs (per } \\
10 \text { years in paid } \\
\text { work) }\end{array}$} & No temporary job (ref.) & - & & & & - & & & \\
\hline & More than one temporary job & 0.052 & (0.021 to 0.084$)$ & 0.001 & 0.129 & 0.025 & ( -0.009 to 0.059$)$ & 0.147 & 0.061 \\
\hline \multirow{2}{*}{$\begin{array}{l}\text { Job changes (per } \\
10 \text { years in paid } \\
\text { work) }\end{array}$} & No change (ref.) & - & & & & - & & & \\
\hline & Two or less changes & 0.007 & $(-0.007$ to 0.021$)$ & 0.341 & 0.017 & 0.000 & $(-0.015$ to 0.016$)$ & 0.976 & 0.001 \\
\hline \multirow{5}{*}{$\begin{array}{l}\text { Number of } \\
\text { unemployment } \\
\text { periods }\end{array}$} & No unemployment period (ref.) & - & & & & - & & & \\
\hline & One unemployment period & 0.028 & (0.007 to 0.048$)$ & 0.009 & 0.067 & 0.016 & $(-0.007$ to 0.038$)$ & 0.179 & 0.037 \\
\hline & $2+$ unemployment periods & 0.063 & (0.024 to 0.103 ) & $<0.001$ & 0.157 & 0.044 & (0.003 to 0.085$)$ & 0.036 & 0.108 \\
\hline & No years out of work (ref.) & - & & & & - & & & \\
\hline & $1-5$ years out of work & 0.012 & $(-0.004$ to 0.028$)$ & 0.153 & 0.028 & 0.003 & $(-0.015$ to 0.020$)$ & 0.758 & 0.007 \\
\hline \multirow{9}{*}{$\begin{array}{l}\text { Mode occupational } \\
\text { position }\end{array}$} & Lower managers and professionals & 0.061 & (0.034 to 0.089$)$ & $<0.001$ & 0.139 & 0.062 & (0.034 to 0.090$)$ & $<0.001$ & 0.141 \\
\hline & Intermediate employee & 0.087 & (0.057 to 0.117$)$ & $<0.001$ & 0.200 & 0.083 & (0.052 to 0.113$)$ & $<0.001$ & 0.190 \\
\hline & Small employers and self-employed & 0.106 & (0.049 to 0.163$)$ & $<0.001$ & 0.245 & 0.100 & (0.044 to 0.157$)$ & 0.001 & 0.233 \\
\hline & Lower grade white collar workers & 0.177 & (0.141 to 0.212$)$ & $<0.001$ & 0.425 & 0.165 & (0.129 to 0.201$)$ & $<0.001$ & 0.396 \\
\hline & Skilled workers & 0.103 & (0.046 to 0.161$)$ & $<0.001$ & 0.239 & 0.098 & (0.040 to 0.156$)$ & 0.001 & 0.227 \\
\hline & Semiskilled or unskilled workers & 0.181 & (0.138 to 0.224$)$ & $<0.001$ & 0.435 & 0.172 & (0.129 to 0.215$)$ & $<0.001$ & 0.413 \\
\hline & Main position unknown & 0.104 & (0.074 to 0.135$)$ & $<0.001$ & 0.241 & 0.101 & (0.070 to 0.132$)$ & $<0.001$ & 0.234 \\
\hline & Promotion (ref.) & - & & & & - & & & \\
\hline & No promotion & -0.001 & $(-0.020$ to 0.017$)$ & 0.888 & -0.003 & -0.003 & $(-0.023$ to 0.016$)$ & 0.739 & -0.008 \\
\hline Lack of promotion & Failed promotion & -0.006 & $(-0.053$ to 0.042$)$ & 0.815 & -0.014 & -0.017 & $(-0.066$ to 0.031$)$ & 0.478 & -0.042 \\
\hline
\end{tabular}

Note: All models are based on multilevel models (individuals nested in health examination centre, adjusted for age, age square, partnership situation and education) (complete case analyses). Model 1 is calculated for each career characteristic separately (separate models). Model 2 includes all career characteristics simultaneously (simultaneous model).

Respondents who retired or had a health-related career interruption prior to age 45 are excluded from the analyses.

$A L$, allostatic load; AME, average marginal effect; ref., reference. 
Table 4 Association between career characteristics and AL index for men $(n=42386)$ : negative binomial regression coefficients ( $\beta)$, confidence intervals, $p$ values and AMEs

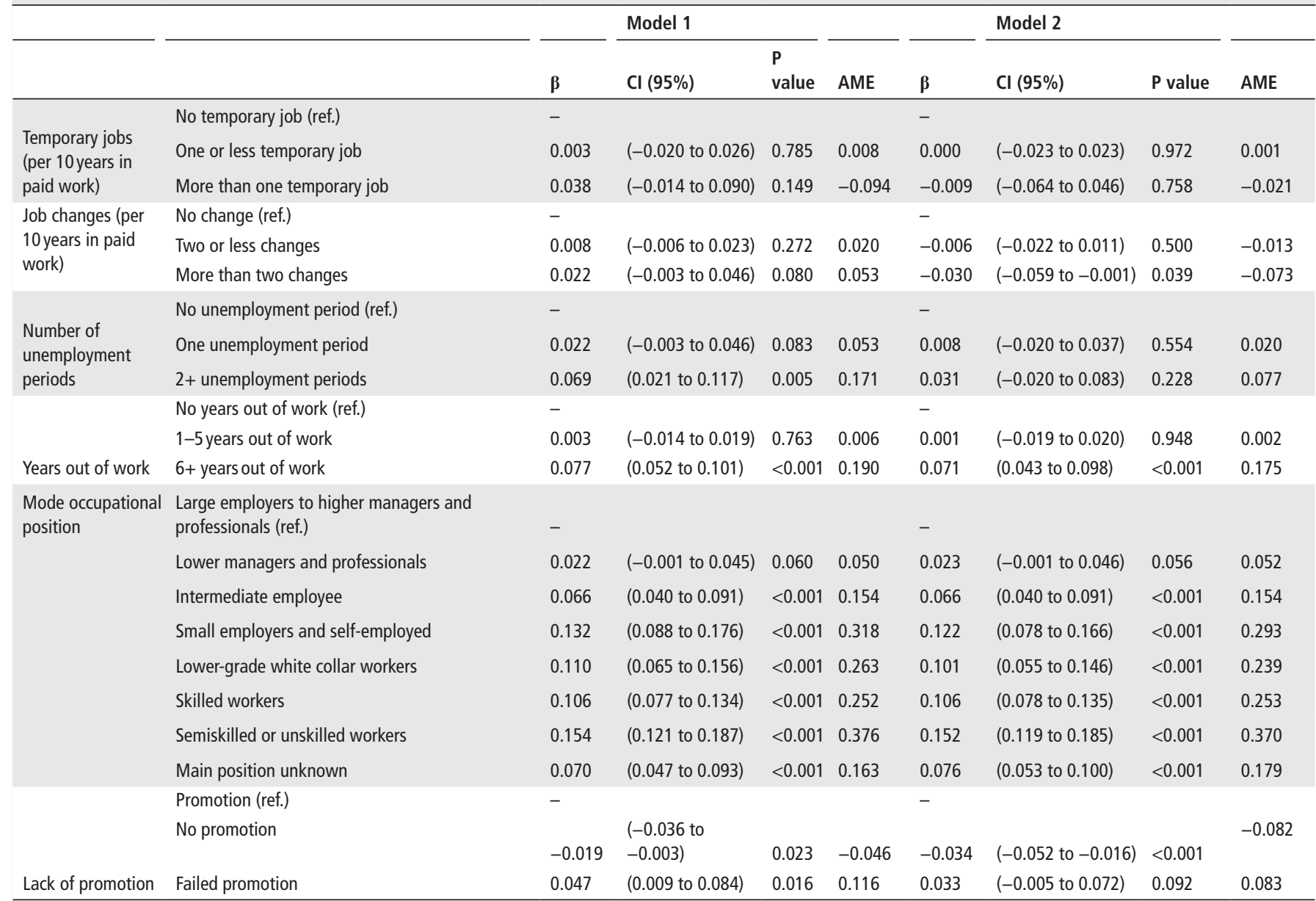

Note: All models are based on multilevel models (individuals nested in health examination centre, adjusted for age, age square, partnership situation and education) (complete case analyses). Model 1 is calculated for each career characteristic separately (separate models). Model 2 includes all career characteristics simultaneously (simultaneous model).

Respondents who retired or had a health-related career interruption prior to age 45 are excluded from the analyses.

$A L$, allostatic load; $A M E$, average marginal effect; ref., reference.

that the reported associations are probably independently related to AL, even after conditioning for the remaining career characteristics.

Findings also remain consistent in sensitivity analyses that additionally adjusted for BMI and activity limitations (online supplemental table 3). In addition, when estimating the associations between career characteristics and each AL biomarker separately (online supplemental tables 4 and 5 and figure 2), we found that associations were similar for most of the biomarkers except of CCR, where associations were not in the expected direction.

To summarise the main findings, figure 1 presents the predicted levels of AL for each category of the career characteristics (as based on model 1 from the regression models), showing again that levels of AL are particularly high for men and women with a continuous disadvantaged occupational position, with repeated periods of unemployment and with years out of work.

\section{DISCUSSION}

This study provides some evidence that adverse employment histories over an extended time period (between age 25 and 45) are related to higher levels of AL beyond age 45, particularly histories that are characterised by a continued disadvantaged occupational position and discontinuous careers that are characterised by repeated periods of unemployment or years out of work. This adds to current knowledge by extending concepts of occupational stress and suggesting that cumulative disadvantage and disruptive elements of employment histories are linked to chronic stress reactions and related physiological processes that lead to a state of AL. Also, by conducting separate analyses for men and women-a distinction that has often been neglected in previous studies ${ }^{28}$-we find that associations were similar for men and women. In addition, findings remained stable after adjusting for partnership history, age and education, as well as after excluding respondents with a health-related career interruption or early retirement, as well as when all career characteristics were included simultaneously into a model (supporting an association with $\mathrm{AL}$ that is independent of the remaining characteristics). However, we also found that some of the studied career characteristics were not clearly related to AL, including the number of temporary jobs for men and the number job changes for both sexes.

Overall, the observed associations for disadvantaged and discontinuous careers are in line with studies that investigated repeated exposure to job insecurity or stress at work in conjunction with health. ${ }^{9}{ }^{29}{ }^{30}$ Findings also correspond to studies on health consequences of continuously disadvantaged socioeconomic positions. ${ }^{31}{ }^{32}$ Yet, by specifying adverse characteristics of 
employment histories over an extended time period of the life course (between 25 and 45), this study adds to existing research. Specifically, we confirm the importance of extending the rather static concepts of stressful work that received main attention in recent research on this topic and of studying the burden of workrelated disease in a life course perspective. ${ }^{82}$ Our study also illustrates the usefulness of a theory-driven approach that specifies adverse characteristics of employment histories based on the notion of recurrent threats to important psychosocial needs of working persons (ie, job security, ${ }^{17}$ control $^{318}$ and reward ${ }^{4}{ }^{19}$ ). The notion of 'employment strain' represents a similar approach towards assessing chronic adversity at work (with a focus on threats to control and autonomy at work ${ }^{33}$ ). Its association with health, though, still needs more empirical research.

The observed differences in associations of the career characteristics under study with AL deserve further methodological as well as conceptual discussion. With regard to measurement, our way of assessing frequency of job changes as an indicator of precarious employment possibly failed to distinguish between involuntary and voluntary (and potentially health-beneficial) changes. Likewise, the nature of temporary jobs may be different for men and women, and future analyses may incorporate information on employment status (eg, self-employed or not), or more information on reasons for not working may be important as well (eg, information on interruptions due to home or family work or because of education). Similarly, in the case of failed promotion, the used categories may also be refined and include information on the class of origin and of destination. At the conceptual level, our finding that AL was associated rather consistently with indicators of career discontinuity (ie, periods of unemployment or years out of work) raises the question whether career discontinuity elicits a particularly high intensity and perseverance of stressful experience due to its disruptive nature. This, in fact, corresponds to earlier research on health impacts of negative life events, suggesting that the extent to which a disruptive event threatens a person's routines of everyday life matters most for stress. $^{34} 35$

Furthermore, our composite score of AL differs to some extent from previous studies, although a standard measure of AL has not yet been established. ${ }^{36}$ Given the restrictions of available data, it includes quite a comprehensive set of indicators representing subclinical (or secondary) aspects, but it contains only a reduced representation of autonomic nervous system, cardiovascular and immune (or primary) parameters. Nevertheless, the fact that associations of employment characteristics with single AL indicators by and large follow the patterns observed for the composite score supports the usefulness of our measure. It also suggests that adverse employment histories are linked to poorer biomarker levels across the four systems involved in AL (see online supplemental tables 4 and 5). The only exception was observed in case of CCR-a finding that is not in line with research supporting socioeconomic inequalities in kidney function, ${ }^{37}$ but that nevertheless corresponds to a previous study that also used CONSTANCES data. ${ }^{7}$ This finding needs additional exploration. In addition, although we followed the most common approach by using high-risk quartiles for each AL biomarker, ${ }^{2}$ we may have adopted alternative methods of calculating the AL index, for example, based on clinical cutpoints for some of the biomarkers. This, however, may result in greater weight to some components than others, while the relative importance of different AL biomarkers in the stress response remains an open question.

The study has several limitations. First, the core measures of our study, career characteristics between ages 25 and 45 years, were collected retrospectively. We thus need to consider a potential recall bias, with a tendency to reduce complexity or to under-report unfavourable events. ${ }^{38}$ Compared with prospective data collection though, our retrospective data make sure that information (referring to different time points) are comparable throughout time, and they do not produce missing data due to panel attrition. There is also increasing support that retrospective data, in particular when asking about sociodemographic conditions and employment histories, ${ }^{39}{ }^{40}$ provide reliable and valid information. Second, although information on employment histories refers to previous life stages, far-reaching conclusions on a causal association are not possible for at least two reasons. First, we again need to consider potential selection into adverse employment histories, where people with poor health are more likely to have adverse careers. We addressed this issue by excluding people with poor health before and during the observation period, but we still cannot fully exclude this selection. Second, while we included a number of potential confounders into the analyses (ie, age, partnership and education), we cannot rule out that other aspects (eg, conditions of material deprivation in early life) act as potential confounders, as well as potential confounding through unobserved factors remains an issue in our observational study. Another limitation relates to the generalisation of results. While our sample represents a large fraction of the French labour market, people who were selfemployed are under-represented because of the sample strategy. Since this group of workers is likely to have less continuous and more insecure careers (eg, due to the expansion of independent contracting ${ }^{41}$ and the gig economy ${ }^{42}$ ), the strength of associations observed in our study may be underestimated.

In conclusion, our study builds on and extends existing research on the impact of psychosocial stress at work on health by analysing adverse employment histories and their properties over an extended time period and their associations with biomarkers of AL. This underlines the importance of physiological responses as a key mechanism through which chronic stress at work is linked to poor health and disease development. Our findings point to a potentially beneficial role of promoting healthy working and employment conditions, particularly among more disadvantaged groups of the labour market in early stages of labour market participation.

\section{What is already known on this subject}

- Previous studies have linked single-point measures of psychosocial stress at work to allostatic load (AL), but current changes in working life necessitate the extensions of concepts of occupational stress by investigating properties of entire employment histories in relation to biomarkers of physiological systems.

\section{What this study adds}

- This study adds to current knowledge by suggesting that cumulative disadvantage and discontinuous careers over the course of an extended time period are linked to chronic stress reactions and related physiological processes that lead to a state of AL for both men and women.

Acknowledgements The authors thank the Caisse Nationale d'Assurance Maladie des Travailleurs Salaries and the Centres d'Examens de Santé of the French Social Security, which are collecting a large part of the data, as well as the Caisse 
Nationale d'Assurance Vieillesse, ClinSearch, Asqualab and Eurocell, which are in charge of the data quality control.

Contributors All authors (MW, TC, MG, MZ, HH and JS) have contributed as follows: MG and MZ designed the study, including quality assurance and control, and helped supervise the field activities and provided the data. MW, TC and JS developed the study's analytical strategy and the conceptual frame of the study. HH helped to conduct the literature review and assisted in the data analyses. MW had the main responsibility for data management and analyses, and drafted the first version of the manuscript. All authors critically reviewed the first draft of the manuscript and approved its submission.

Funding This work was supported by funding from the German research foundation (Deutsche Forschungsgemeinschaft), project number: SI 236/16-1 and WA 3065/5-1). The CONSTANCES Cohort Study was supported and funded by the Caisse Nationale d'Assurance Maladie des Travailleurs Salariés. The CONSTANCES Cohort Study is an 'Infrastructure nationale en Biologie et Santé' and benefits from a grant from ANR (ANR-11-INBS-0002). CONSTANCES is also partly funded by MSD, AstraZeneca and Lundbeck.

Competing interests None declared.

Patient consent for publication Consent obtained directly from patient(s).

Ethics approval The study was approved by bodies regulating ethical data collection in France (Comité Consultatif pour le Traitement des Informations Relatives à la Santé and Commission Nationale Informatique et Liberté), and participants signed an informed consent.

Provenance and peer review Not commissioned; externally peer reviewed.

Data availability statement Data may be obtained from a third party and are not publicly available.

Supplemental material This content has been supplied by the author(s). It has not been vetted by BMJ Publishing Group Limited (BMJ) and may not have been peer-reviewed. Any opinions or recommendations discussed are solely those of the author(s) and are not endorsed by BMJ. BMJ disclaims all liability and responsibility arising from any reliance placed on the content. Where the content includes any translated material, BMJ does not warrant the accuracy and reliability of the translations (including but not limited to local regulations, clinical guidelines, terminology, drug names and drug dosages), and is not responsible for any error and/or omissions arising from translation and adaptation or otherwise.

Open access This is an open access article distributed in accordance with the Creative Commons Attribution Non Commercial (CC BY-NC 4.0) license, which permits others to distribute, remix, adapt, build upon this work non-commercially, and license their derivative works on different terms, provided the original work is properly cited, appropriate credit is given, any changes made indicated, and the use is non-commercial. See: http://creativecommons.org/licenses/by-nc/4.0/.

\section{ORCID iDs}

Morten Wahrendorf http://orcid.org/0000-0002-4191-1420

Tarani Chandola http://orcid.org/0000-0002-1864-3413

\section{REFERENCES}

1 McEwen BS. Protective and damaging effects of stress mediators. N Engl J Med 1998:338:171-9.

2 Seeman TE, Singer BH, Rowe JW, et al. Price of adaptation--allostatic load and its health consequences. MacArthur studies of successful aging. Arch Intern Med 1997;157:2259-68

3 Karasek R, Theorell T. Healthy work. New York: Basic Books, 1990.

4 Siegrist J. Adverse health effects of high-effort/low-reward conditions. I Occup Health Psychol 1996;1:27-41.

5 Eddy P, Wertheim EH, Hale MW, et al. A systematic review and meta-analysis of the effort-reward imbalance model of workplace stress and hypothalamic-pituitaryadrenal axis measures of stress. Psychosom Med 2018;80:103-13.

6 Mauss D, Li J, Schmidt B, et al. [Work-related stress and the allostatic load index - a systematic review]. Gesundheitswesen 2017;79:e134-44.

7 Magnusson Hanson LL, Westerlund H, Goldberg M, et al. Work stress, anthropometry, lung function, blood pressure, and blood-based biomarkers: a cross-sectional study of 43,593 French men and women. Sci Rep 2017;7:9282.

8 Wahrendorf M, Chandola T. A life course perspective on work stress and health. In: Siegrist J, Wahrendorf M, eds. Work stress and health in a globalized economy: the model of Effort-Reward imbalance. Heidelberg: Springer, 2016: 46-66.

9 Coronado IIC, Chandola T, Steptoe A. Allostatic load and Effort-Reward imbalance: associations over the Working-Career. Int J Environ Res Public Health 2018;15:191.
10 Kalleberg AL, Work P. Precarious work, insecure workers: employment relations in transition. Am Sociol Rev 2009;74:1-22.

11 Kuh D, Ben-Shlomo Y. A life course approach to chronic disease epidemiology. Vol 2. Oxford university press 2004

12 Lacey RE, Sacker A, Kumari M, et al. Work-family life courses and markers of stress and inflammation in mid-life: evidence from the National child development study. Int J Epidemiol 2016;45:1247-59.

13 Sabbath EL, Guevara IM, Glymour MM, et al. Use of life course work-family profiles to predict mortality risk among US women. Am J Public Health 2015;105:e96-102.

14 Tosi M, Grundy E. Work-family lifecourses and later-life health in the United Kingdom. Ageing Soc 2021;41:1371-97.

15 Ice E, Ang S, Greenberg K, et al. Women's Work-Family histories and cognitive performance in later life. Am J Epidemiol 2020;189:922-30.

16 Wahrendorf M, Hoven $\mathrm{H}$, Goldberg M, et al. Adverse employment histories and health functioning: the CONSTANCES study. Int J Epidemiol 2019;48:402-14.

17 Jahoda M. Employment and unemployment: a social-psychological analysis. CUP Archive 1982.

18 Deci EL, Ryan RM. Overview of self-determination theory: an organismic dialectical perspective. Handbook of self-determination research 2002;2:3-33.

19 Greenberg J, Cohen RL. Why justice? normative and instrumental interpretations. equity and justice in social behavior. Amsterdam: Elsevier, 1982: 437-69.

20 Kuh D, Karunananthan S, Bergman H, et al. A life-course approach to healthy ageing: maintaining physical capability. Proceedings of the Nutrition Society 2014;73:237-48.

21 Goldberg M, Carton M, Descatha A, et al. CONSTANCES: a general prospective population-based cohort for occupational and environmental epidemiology: cohort profile. Occup Environ Med 2017;74:66-71.

22 Rose D, Harrison E. The European socio-economic classification: a new social class schema for comparative European research. European Societies 2007:9:459-90.

23 Seeman T, Epel E, Gruenewald T, et al. Socio-Economic differentials in peripheral biology: cumulative allostatic load. Ann N Y Acad Sci 2010;1186:223-39.

24 Cockcroft DW, Gault MH. Prediction of creatinine clearance from serum creatinine. Nephron 1976;16:31-41.

25 Long JS, Freese J. Regression models for categorical dependent variables using Stata, revised edition. College Station: Stata Press, 2003.

26 Williams R. Using the margins command to estimate and interpret adjusted predictions and marginal effects. Stata J 2012;12:308-31.

27 Westreich D, Greenland S. The table 2 fallacy: presenting and interpreting confounder and modifier coefficients. Am J Epidemiol 2013;177:292-8.

28 McMunn A. Gender differences in the health effects of psychosocial factors. In: Kivimäki MBG, Steptoe A, eds. Handbook of psychosocial epidemiology. London: Routledge Taylor and Francis, 2018.

29 Chandola T, Brunner E, Marmot M, Chandola, Brunner M. Chronic stress at work and the metabolic syndrome: prospective study. BMJ 2006;332:521-5.

30 Trudel X, Brisson C, Milot A, et al. Adverse psychosocial work factors, blood pressure and hypertension incidence: repeated exposure in a 5-year prospective cohort study. $J$ Epidemiol Community Health 2016;70:402-8.

31 Stringhini S, Zaninotto P, Kumari M, et al. Socio-Economic trajectories and cardiovascular disease mortality in older people: the English longitudinal study of ageing. Int J Epidemiol 2018;47:36-46.

32 Robertson T, Popham F, Benzeval M. Socioeconomic position across the lifecourse \& allostatic load: data from the West of Scotland Twenty-07 cohort study. BMC Public Health 2014;14:1-9.

33 Lewchuk W, De Wolff A, King A. From job strain to employment strain: health effects of precarious employment. Just Labour 2003;3.

34 Dohrenwend BS, Dohrenwend BP. Stressful life events: their nature and effects. Hoboken: John Wiley \& Sons, 1974

35 Marris P. Loss and change (psychology revivals): revised edition. Milton: Routledge, 2014.

36 Johnson SC, Cavallaro FL, Leon DA. A systematic review of allostatic load in relation to socioeconomic position: poor fidelity and major inconsistencies in biomarkers employed. Soc Sci Med 2017;192:66-73.

37 Zeng X, Liu J, Tao S, et al. Associations between socioeconomic status and chronic kidney disease: a meta-analysis. J Epidemiol Community Health 2018;72:270-9.

38 Krinsley KE, Gallagher JG, Weathers FW, et al. Consistency of retrospective reporting about exposure to traumatic events. J Trauma Stress 2003;16:399-409.

39 Baumgarten M, Siemiatycki J, Gibbs GW. Validity of work histories obtained by interview for epidemiologic purposes. Am J Epidemiol 1983;118:583-91.

40 Wahrendorf M, Marr A, Antoni M, et al. Agreement of self-reported and administrative data on employment histories in a German cohort study: a sequence analysis. Eur J Popul 2019:35:329-46.

41 Eichhorst W, Marx P, Wehner C. Labor market reforms in Europe: towards more flexicure labor markets? J Labour Mark Res 2017:51:1-17.

42 Freni-Sterrantino A, Salerno V. A plea for the need to investigate the health effects of Gig-Economy. Front Public Health 2021;9:63. 